\title{
Vaccination of immune compromised children-an overview for physicians
}

\author{
Laure F. Pittet ${ }^{1,2,3} \cdot$ Klara M. Posfay-Barbe ${ }^{2,3}$ (DD
}

Received: 29 May 2020 / Revised: 9 February 2021 / Accepted: 17 February 2021 / Published online: 5 March 2021

(C) The Author(s) 2021

\begin{abstract}
Immune compromised children are threatened by a higher risk of infections; some of these are preventable by vaccination. Primary care physicians play a fundamental role in optimising vaccination status. In this narrative review, we present the evidence on vaccine safety and immunogenicity in immune compromised children and discuss in which conditions liveattenuated vaccines can possibly be used. Vaccination schedules differ in some of these conditions, including the use of vaccines with higher antigenic contents (e.g. high-dose hepatitis B vaccine), additional vaccine doses (e.g. 2-dose schedule meningococcal vaccine), more frequent booster doses (e.g. life-long pneumococcal vaccine booster), supplementary vaccines (e.g. meningococcal B vaccine) and use of vaccines beyond the age of usual recommendation (e.g. Haemophilus influenza type b vaccine after 5 years of age). Serological monitoring is a useful tool for customizing vaccination schedule in immune compromised children, confirming adequate vaccine response and documenting seroprotection (especially against measles and varicella). Finally, verification of vaccination status of all household members can prevent them being vector of transmission of an infection to the immune compromised children. Conclusion: Intensified information strategies are needed to improve trust, rectify perceived risks and improve vaccine acceptability; primary physicians can play a critical role in the latter.
\end{abstract}

What is Known:

- Physician's awareness is key to success, since it repeatedly correlates with higher vaccination rates

What is New:

- The vaccination status of immunocompromised children is rarely up-to-date

- Knowing the latest vaccine recommendations is challenging, as they differ for each medical condition and change periodically

- This review summarises the vaccine recommendations for children with compromised immune systems and highlights how paediatricians play a key role in coordinating their application

Keywords Immunosuppression $\cdot$ Immunization $\cdot$ Vaccine-preventable diseases $\cdot$ Paediatrician

Communicated by Nicole Ritz

Klara M. Posfay-Barbe

Klara.PosfayBarbe@hcuge.ch

Laure F. Pittet

laure.pittet@hcuge.ch

1 Infectious Diseases Unit, Royal Children's Hospital Melbourne, Parkville, Victoria, Australia

2 Unit of Pediatric Infectious Diseases, Division of General Pediatrics, Department of Pediatrics, Gynecology \& Obstetrics, Children's Hospital, University Hospitals of Geneva, 6 Rue Willy Donzé, 1211 Geneva, Switzerland

3 Faculty of Medicine, University of Geneva, Rue Michel-Servet 1, 1211 Geneva, Switzerland
Abbreviations
IBD Inflammatory bowel disease
HBV Hepatitis B virus
HIV Human immunodeficiency virus
HPV Human papilloma virus
LAV Live-attenuated vaccine
MCV Meningococcal conjugate vaccine
MMR Measles-mumps-rubella
PCV Pneumococcal conjugate vaccine
RSV Respiratory syncytial virus 


\section{Introduction}

Protecting immune compromised children against infections is challenging and is a problem of growing importance. Indeed, paediatrician are dealing with more and more patients with deficient immune system, as (i) immunosuppressive therapies are increasingly used in various medical conditions and (ii) the life expectancy of patients with these conditions has substantially raised. The quality of life of these children has also improved over the years: they are able to attend school, travel and be active in their community. This inevitably puts them in contact with others and a variety of infectious pathogens. Moreover, the frequent hospital admission and outpatient visits associated with chronic diseases inevitably increase their risk of nosocomial exposure to pathogens.

Vaccination has repeatedly been recognised as one of the most important and most cost-efficient invention in healthcare [1]. Vaccine-preventable diseases occur more frequently and have a worst outcome in immunocompromised individuals. In a retrospective cohort study of nearly 7000 paediatric solid organ recipients, $15.6 \%$ were hospitalised for a vaccinepreventable diseases in the first 5 years following transplantation, an 87-fold higher rate compared with the general population [2]. Worst outcomes are well illustrated by the severity of measles infection, which carries a $40 \%$ to $70 \%$ fatality rate among immunocompromised patients, despite adequate treatment, up to 35-fold higher compared with immunocompetent hosts [3]. Measles and other vaccine-preventable diseases have recently re-emerged in many regions, mostly due to declining vaccine uptake $[4,5]$. As herd protection cannot be relied on, prevention of vaccine-preventable diseases in vulnerable population is key.

The aim of this review is to present an overview of the knowledge in the field, provide tables and references that could help primary care physicians when managing immune compromised children. The following questions are addressed: Which fundamental role do primary care physicians play? Who are immune compromised children? Why are their vaccinations status not up-to-date? Are vaccines immunogenic and safe in immune compromised children? Is the vaccination schedule the same than for healthy children? Which additional vaccines are recommended? Why/when should vaccine-preventable diseases serology be monitored? In which situation can live-attenuated vaccine be administrated? Recommendation for passive immunisation are beyond the scope of this review, but details can be find elsewhere $[6,7]$.

\section{Which fundamental role does the primary care physician play}

The primary care physician plays a critical role in optimising their patients' protection against vaccine-preventable diseases.
The first step is to identify within all their patients which are the ones who could benefit from an enhanced protection. When a child has a new diagnosis, and the immune system is likely to be affected, a quick review of the patient's vaccination history should be automatic. The ascertainment of the patient's protection status should rely on checking their records or serologies, as trusting oral recall only can lead to undervaccination or overimmunization [44]. Primary care physicians have a key role to play in discussing with families on the importance of vaccination and reassurance on their safety. In collaboration with a specialist team, a customised vaccination schedule could be planed and anticipated, aiming to immunise, for example, early in the disease process, anticipating periods of higher immunosuppression. This schedule should catch up missing vaccination and add the supplementary vaccines when needed. If recommended, vaccine seroresponses should be checked following vaccination and during follow-up visits.

Another fundamental role of the primary care physician is to ensure that all household members have their vaccinations updated. This "cocooning" strategy is a form of indirect protection for non-immune children, or for those who are unable to be vaccinated. Cocooning is, however, usually not sufficient to fully protect these children, especially those with normal lifestyles.

\section{Who are immune compromised children}

Immunodeficiency can be primary or acquired, secondary to a disease, infection, medication, chronic organ failure or other state (e.g. malnutrition, young age) [8]. Medications can affect the immune system either as an undesirable side effect (e.g. chemotherapy, drug-induced neutropenia) or intentionally in conditions in which the immune response has to be restrained, e.g. management of autoimmune disorders and immunemediated diseases, allergic disorders or solid organ transplant. The most common conditions encountered in daily practice are listed in Table 1.

\section{Why are immune compromised children's vaccination status not up-to-date}

Although vaccinations seem particularly indicated in this high-risk population, immune compromised children are often less adequately vaccinated than healthy children [9-11]. As vaccines and booster doses are given regularly throughout childhood, most children may not have completed their schedule before the onset of immunosuppression. But the main reasons underlying non-vaccination are summarised in Fig. 1 [11-13]. Moreover, as vaccination guidelines change frequently, and differ for each different medical condition, it is 


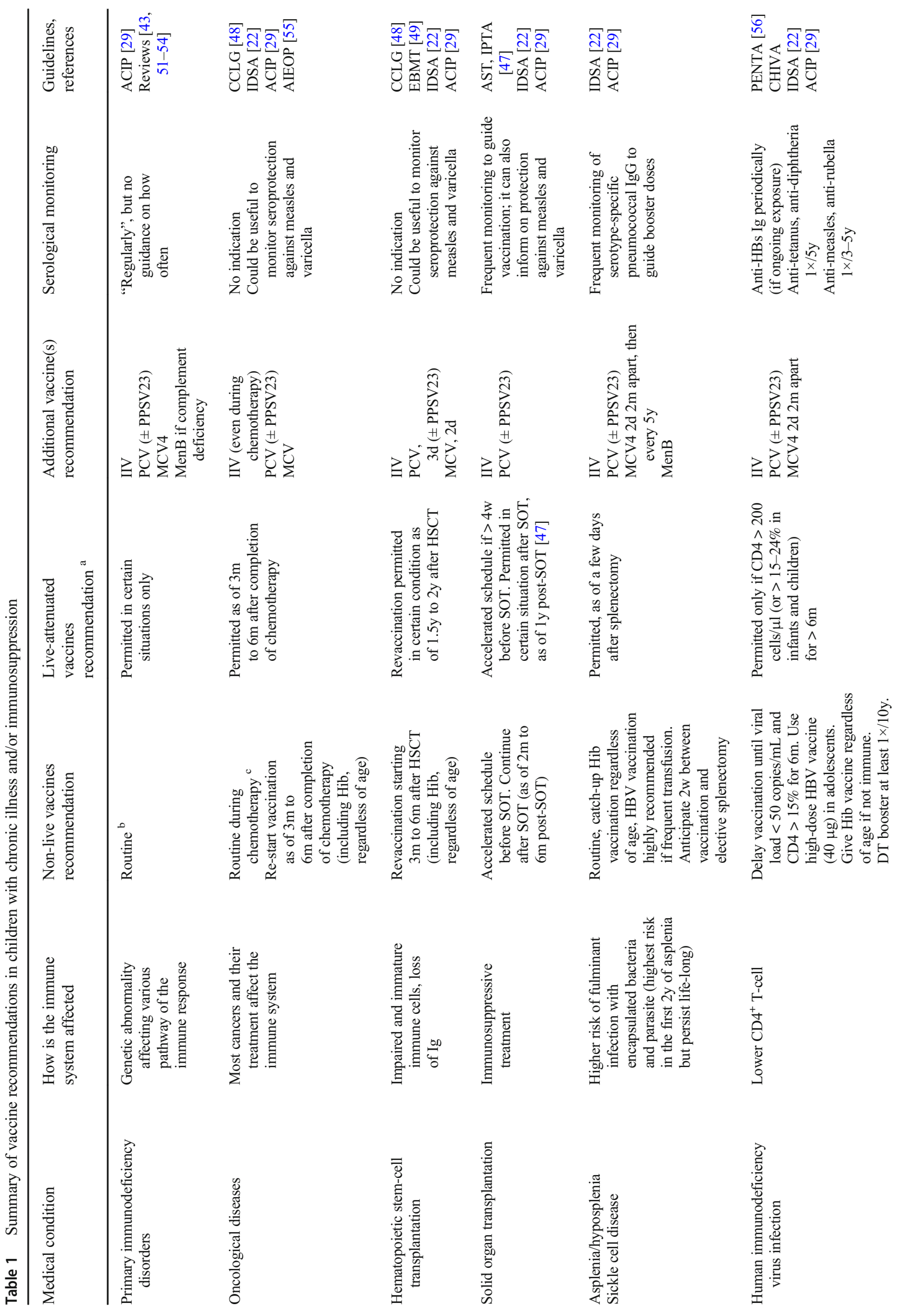




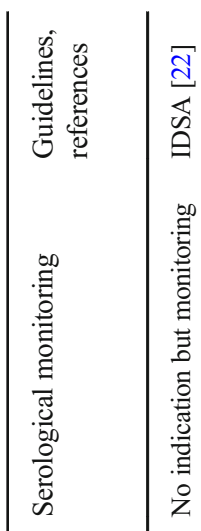

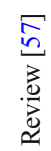

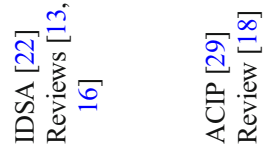

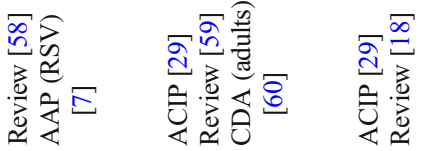

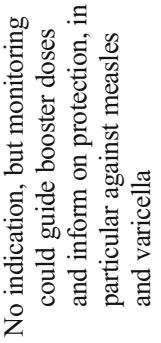

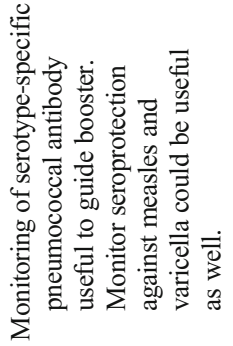

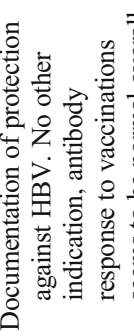

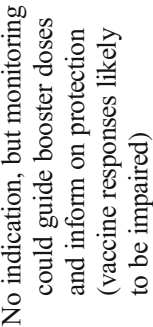

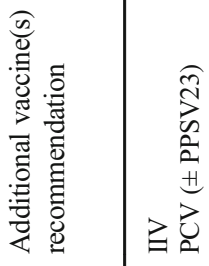

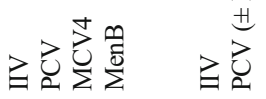

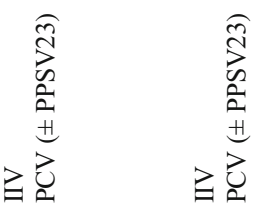

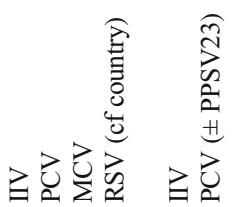

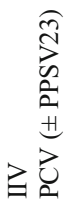

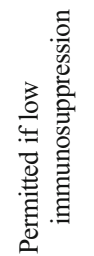

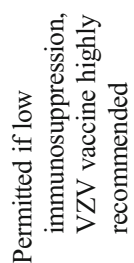

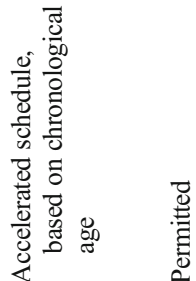
蛋

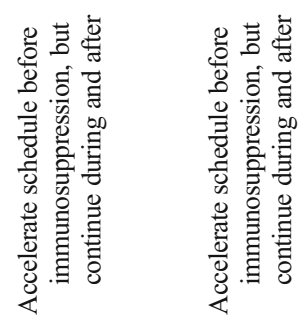

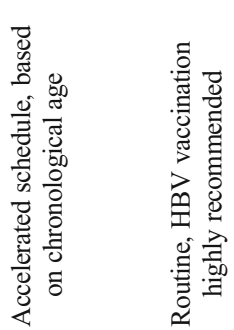

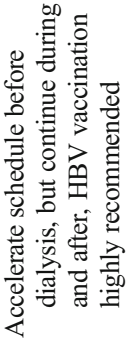
竞

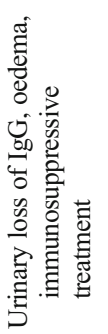

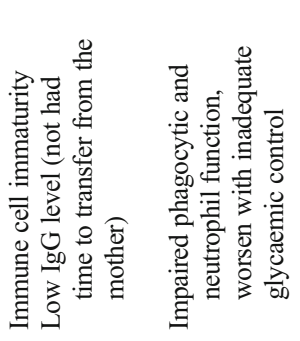
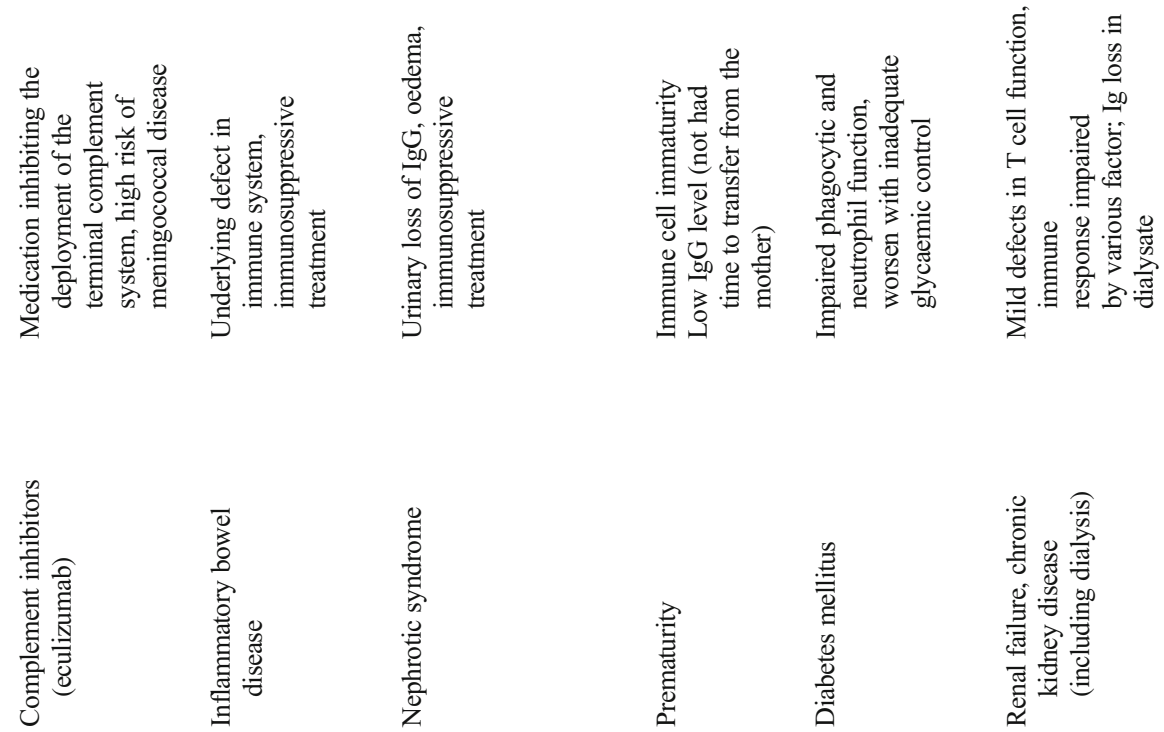

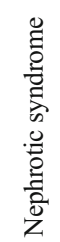

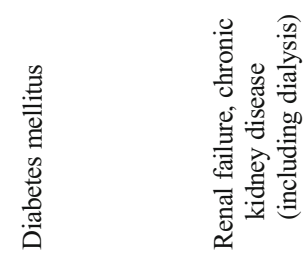

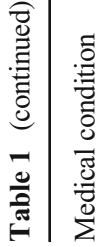




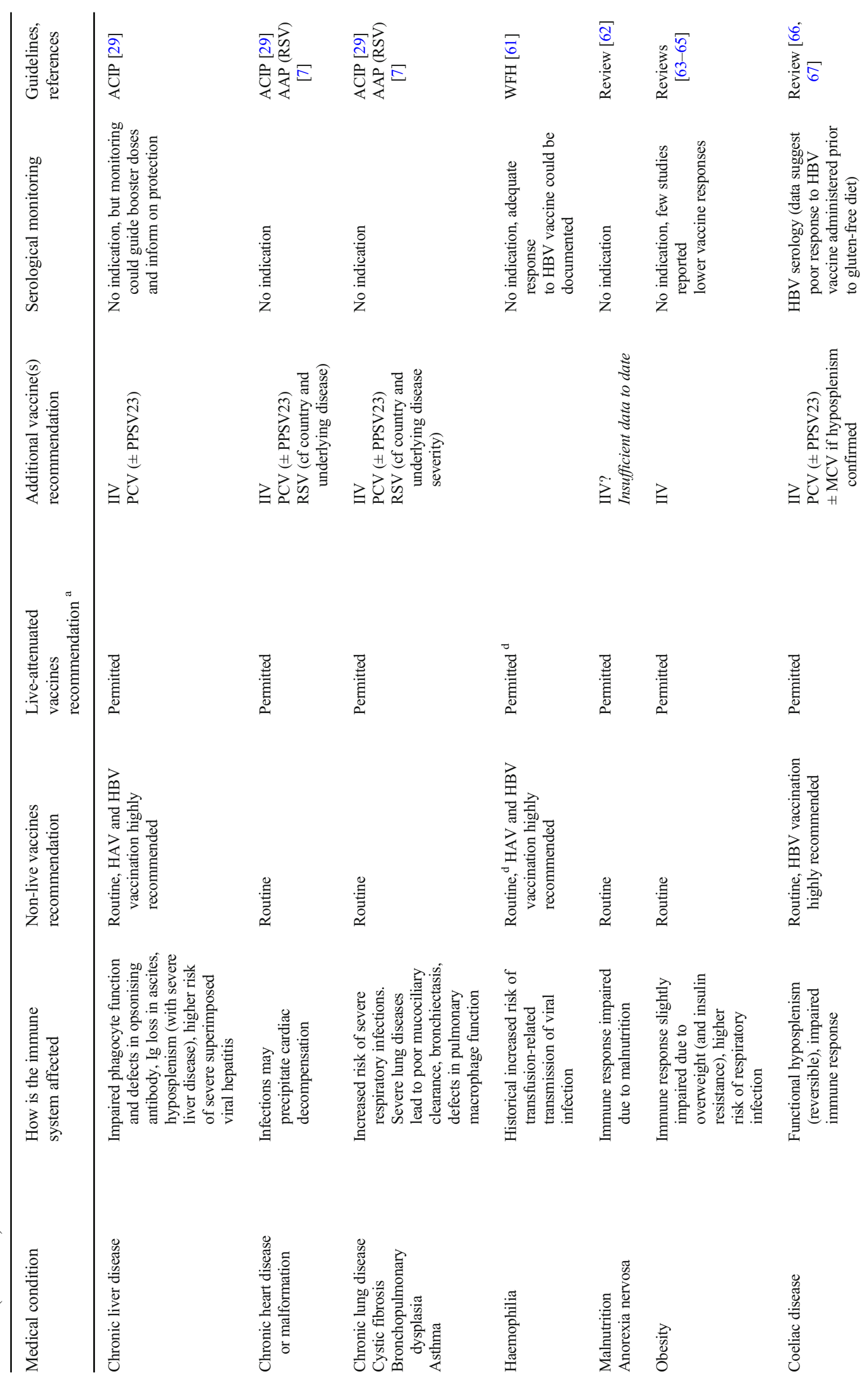




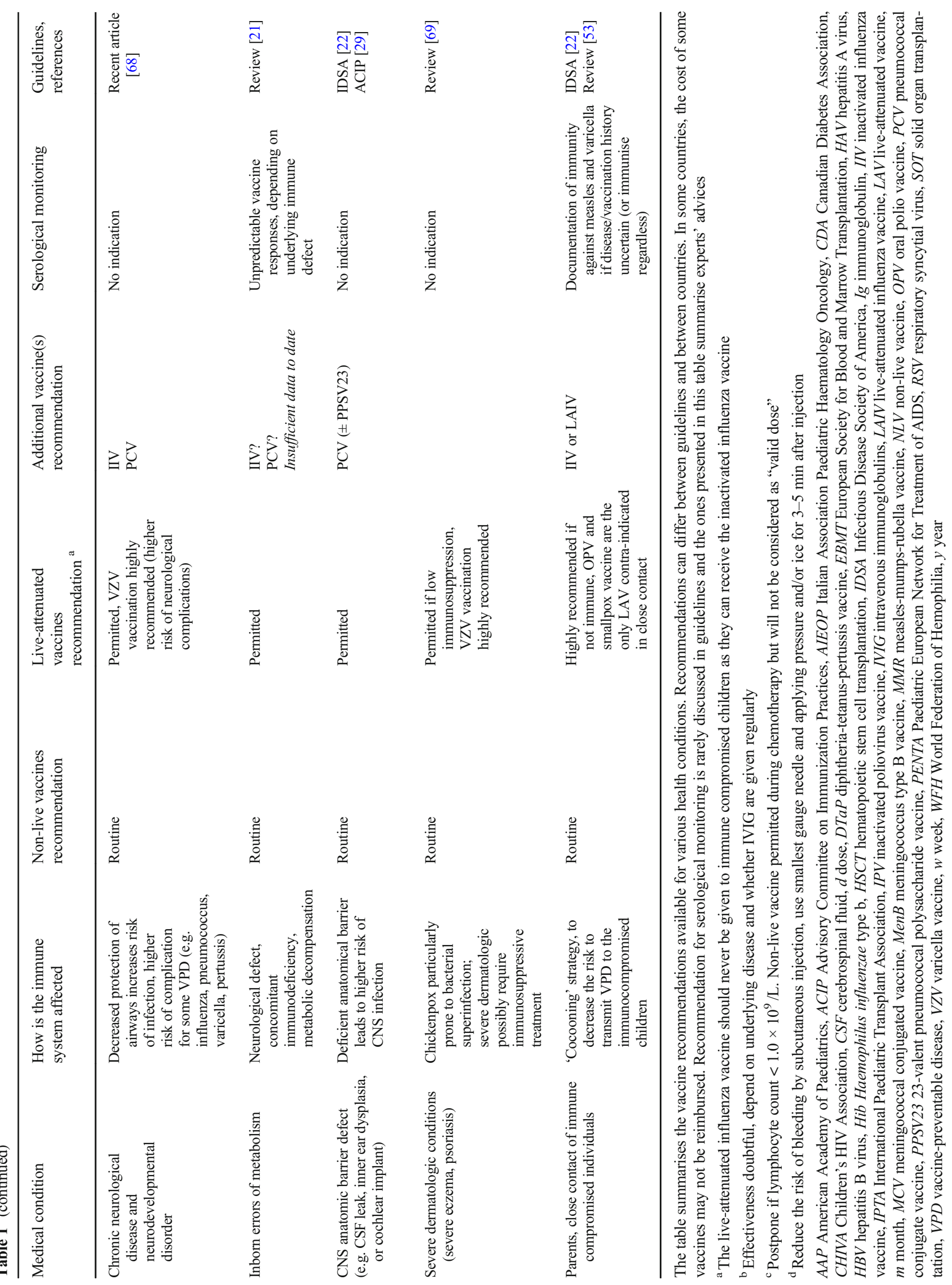


challenging to stay up-to-date with the most recent, specific recommendations [14]. As an example, it was recently reported in patients with inflammatory bowel disease (IBD) that vaccination was the least frequently followed quality of care recommendation [15]. In Italy, vaccination rates in children with HIV, cystic fibrosis, liver transplantation or diabetes were low against pneumococcus $(<25 \%)$ and highly variable for influenza (21\% to 90\%) [11]. Information and better communication appear to be key components for increasing vaccination uptake; primary care physician usually excels in both, being trusted by and close to the patient's family (Fig. 2).

\section{Are vaccines immunogenic in immune compromised children}

Concern on vaccine effectiveness is often an obstacle to vaccination in immune compromised children; immune response to vaccination can be suboptimal [16]. Vaccine responses may be reduced in both magnitude and durability, explaining the need for repeated monitoring of antibody levels during follow-up. However, even in highly immunocompromised hosts, vaccination may induce at least some immune response that could be beneficial in case of further encounter with the pathogen. Vaccines should therefore be administered despite possible non-responsiveness; in some medical conditions, monitoring of antibody concentration is recommended (Table 1).

\section{Are vaccines safe in immune compromised children}

Whereas immunogenicity is an important aspect, vaccine safety is often the main concern of parents and healthcare practitioners. Live-attenuated vaccines (LAV), in particular, are usually avoided in the immunocompromised hosts as they could theoretically induce vaccine-strain infections; these are discussed in detail in a section below. In contrast, non-live vaccines are incapable of causing infection, since they consist in inactivated toxins (protein), in pathogen that have been killed (inactivated) or in only specific segments of the pathogen (subunit, polysaccharides) that may be conjugated to a protein (conjugate vaccine) to enhance the immunological

- Lack of knowledge, patient not recognised as immunocompromised

- Absence of specific recommendation or contra-indication

- Severity of underlying disease

- Concern on vaccine effectiveness

- Misperception regarding safety and fear of adverse events

- Parent refusal

- Sporadic contact with primary care physician

- Confusion regarding the role that specialty care providers vs.

primary care providers play in a patient's overall care

Fig. 1 Common barriers to vaccination

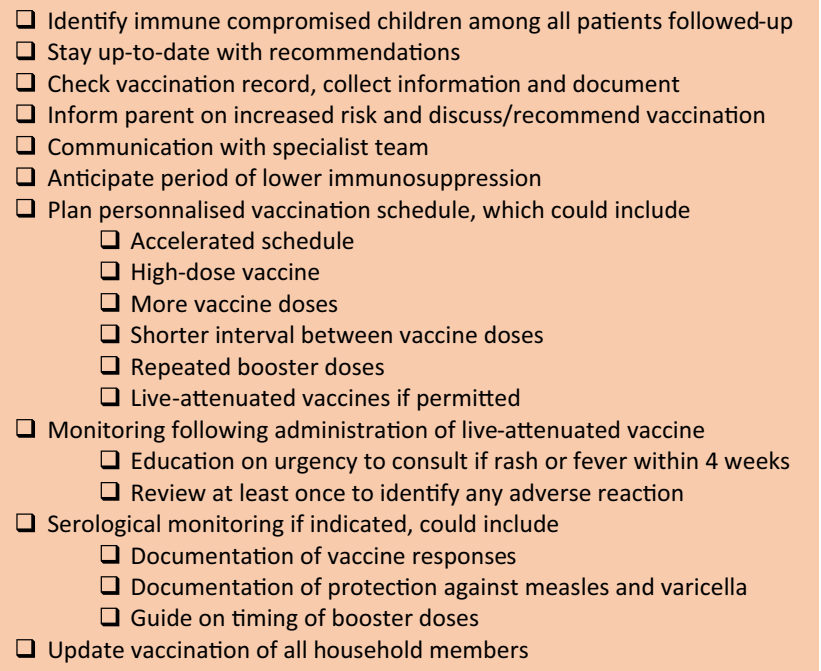

Fig. 2 Checklist for primary care physician in optimising patients' protection

response (Table 2). These vaccines can be given to immunocompromised patient without any safety concerns, as demonstrated in many studies in patients with chronic diseases, e.g. in HIV-infected individuals [17], patients with immunemediated diseases [16], chronic kidney diseases [18] and solid organ transplantation recipients [19]. Therefore, information is critical to clearly explain the expected benefit to the patient.

Proper communication is particularly important for patients with immune-mediated diseases, inborn error of metabolism or solid organ transplantation, for which questions about the inflammation induced by vaccination could play a role in modulating the auto-immune response or inducing a metabolic crisis. Moreover, since the medical conditions of these children will be lifelong, vaccinations cannot be postponed indefinitely. Therefore, in these children, while it is important as for all children to monitor possible side effects of vaccination, the effect of the vaccine on the underlying condition should also be reported, such as signs of graft rejection or flare in disease activity. However, there is increasing data suggesting that concerns regarding the risk of disease exacerbation are unfounded, with numerous studies showing that immunization did not induce significant worsening of underlying disease $[16,19-21]$.

\section{Is the vaccination schedule the same than for healthy children}

The vaccination schedules are usually the same; they slightly differ from those of healthy children in that they may include supplementary vaccinations (for example usually not given beyond a certain age), accelerated schedule, extra doses for primary vaccination, extra boosters, as well as specific 

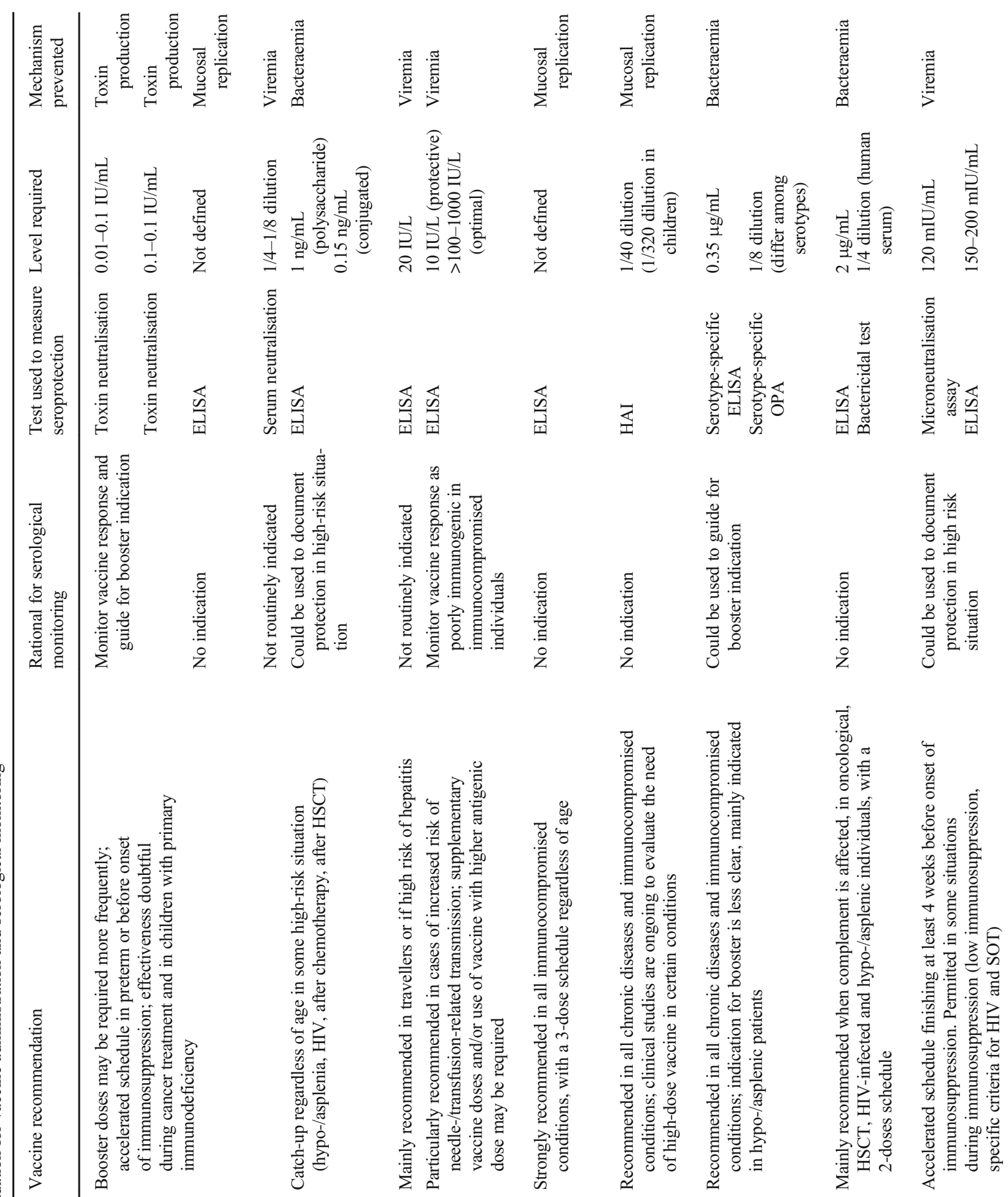

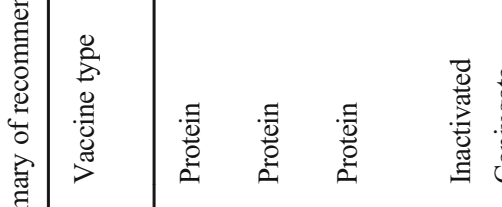
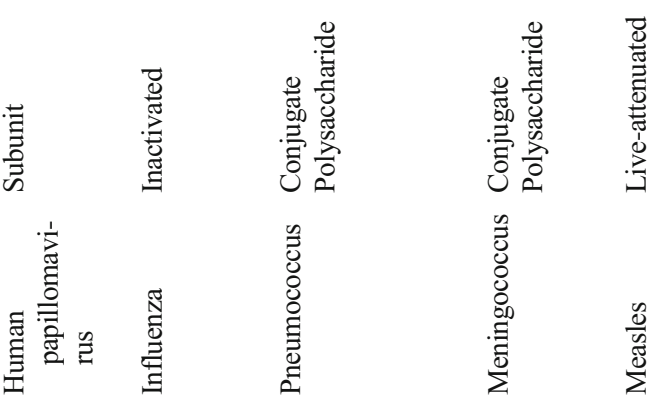


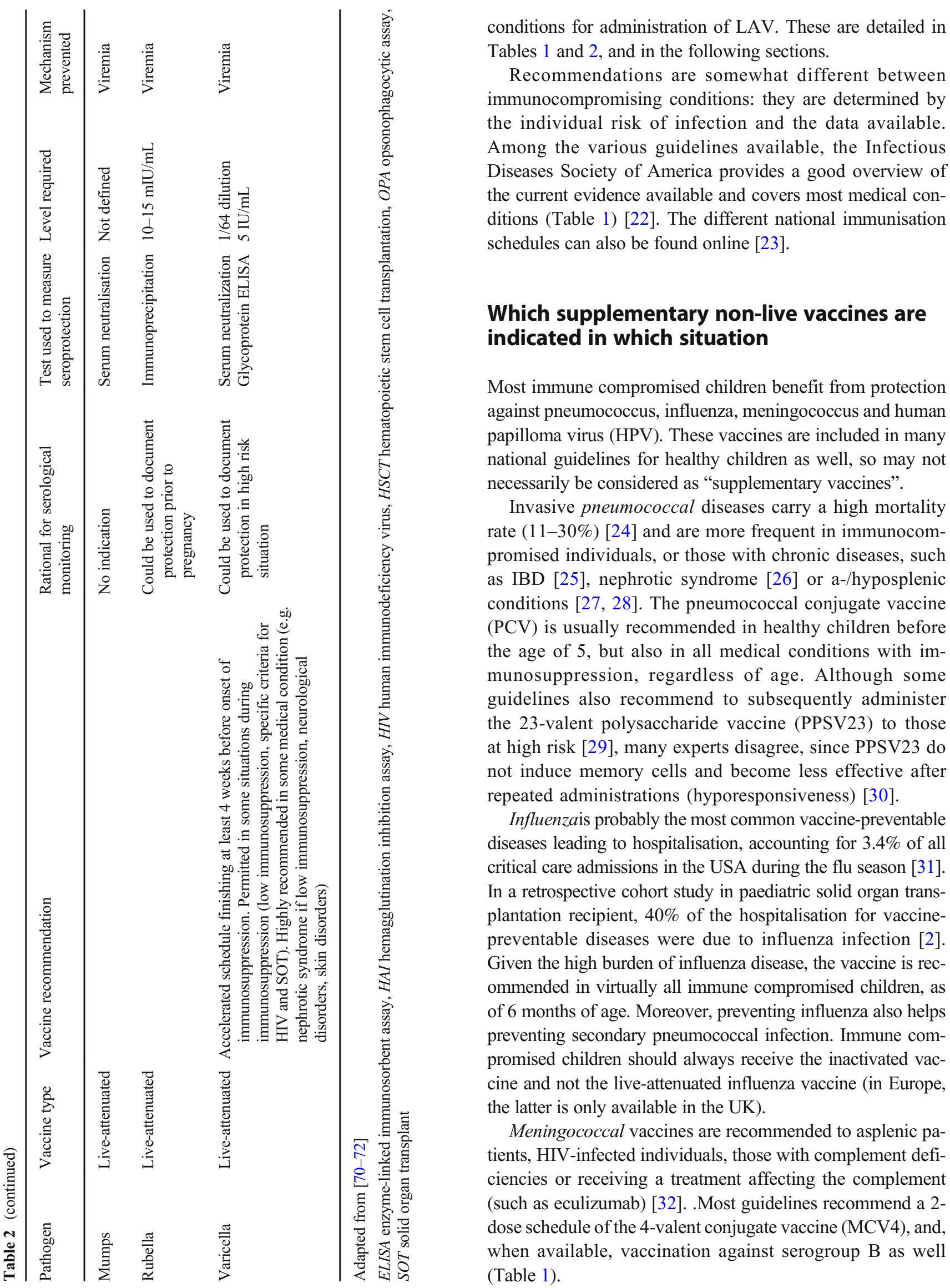


As the risk of malignancy related to $H P V$ is highly increased (up to 100-fold) in immunocompromised individuals [33], a 3-dose schedule is strongly recommended for all. The 2 -doseschedule-used routinely in immunocompetent 11-15-year-old individuals - may not be sufficiently immunogenic, reason why the 3-dose schedule should be preferred [34].

\section{Do immune compromised children need more or higher doses}

As vaccination may be less immunogenic in immune compromised children and immunity may wane faster, it is sometimes useful to administer vaccines with higher antigenic contents, additional vaccine doses or more frequent booster doses to ensure adequate response (via serological monitoring, as discussed below) and subsequent protection against vaccinepreventable diseases.

High-dose vaccine For vaccination against HBV per example, use of high-dose vaccine is recommended by some experts in HIV-infected adolescents (and adult), haemodialysis adult, and studies involving adults suggest it could be beneficial for oncological patients, or those with immune-mediated diseases [22]. Another example is the high-dose influenza vaccine being currently evaluated in immunocompromised individuals, including oncological patients, solid organ transplantation recipients and haemodialysis patients [35-37]. Data in paediatric patients, however, is scarce.

More vaccine doses Regarding schedule, 3-dose(rather than 2-doses) schedule are recommended for HPV in all immunocompromised condition, and a 2-dose (rather than single dose) schedule is recommended for MCV4 [22].

More boosters Regular MCV and PCV booster are recommended in some immunocompromised condition, whereas they are not recommended in healthy children. Diphtheriatetanus booster doses are recommended more often as well, as guided by serological monitoring.

\section{The rationale behind serological monitoring}

One of the most useful tools for customization of vaccination schedule in immune compromised children is to regularly monitor their serologies [38]. In children receiving chemotherapy for example, there is strong evidence to suggest that antibody concentrations wane more rapidly during treatment [39]. Cut-off values for seroprotection (i.e. correlates of protection) are available for most vaccine-preventable diseases (Table 2), but may vary slightly between laboratories. These measures allow to (i) confirm adequate vaccine response, (ii) guide when to administer a booster dose and (iii) document current protection against vaccine-preventable diseases. The latter is of particular importance for varicella and measles viruses, for which the reported mortality rates in infected immunocompromised hosts are up to $25 \%$ and $70 \%$, respectively [3, 40, 41]. For both viruses, absence of seroprotection would require prompt management following contact (intravenous immunoglobulins and/ or antiviral therapy), whereas documentation of highly seroprotective titres could suggest a "wait and see" attitude [42]. Physician can therefore inform individually on the risk of severe disease following contact with varicella or measles and provide guidance on what to do if this situation occurs. Regular monitoring of serologies against vaccine-preventable diseases has been adopted by many as an important part of the regular follow-up of immunocompromised patient. Although this test does not measure the other actors of the immune response, it is the only indirect measure of protection available. There is, however, no clear recommendation on when, in whom and how often should serology be assessed (Tables 1 and 2). Annual monitoring of serologies may be indicated in highly immunocompromised patients, or when the immunosuppressing regimen has recently been increased, whereas less frequent monitoring (i.e. once every 5 years) should probably be enough in well-controlled HIV-infected individuals, for example.

\section{In which situation can live-attenuated vaccines be administered}

When vaccinating immunocompromised individuals, the most important safety issue concerns LAV. They consist in live pathogens that have been 'weakened' so that they can still replicate but with difficulty and without having the capacity to cause the disease in an immunocompetent host. Given the fear of a theoretical uncontrolled replication that could lead to severe vaccine-induced disease, LAV are mostly contraindicated in immune compromised children. In patients with severe primary immunodeficiency disease (e.g. severe combined immunodeficiency), LAV carry a significant risk of vaccine-strain infections, which have been reported following the oral rotavirus or poliovirus vaccines, measles-mumpsrubella(MMR) vaccine and bacille Calmette-Guérin vaccine $[43,44]$. However, there is growing evidence documenting the safety of immunising immunocompromised hosts with different types of LAV in carefully selected settings.

MMR and varicella vaccines are usually well tolerated in case of milder immunosuppression, such as in children with DiGeorge syndrome (if lymphocyte count is $>500$ cells $/ \mu \mathrm{L}$ ) [43], HIV-infected individuals (if CD4 count is $>200$ cells $/ \mu \mathrm{L}$ ) $[45,46]$, liver or kidney transplant recipients (strict conditions [47]), after hematopoietic stem cell transplantation [48, 49], or in individuals with immune-mediated diseases on low/no immune suppression [16, 22], including children with nephrotic 
syndrome [50]. MMR and varicella vaccine have indeed the potential to protect patients against threatening pathogen that are endemic or linked with epidemics in many places around the world. However, extra caution should be taken and close safety monitoring is highly recommended following the administration of LAV in any situation when the immune system is affected [22, 47]. In the setting of solid organ transplantation, a consensus of worldwide experts has recommended the following surveillance: (i) education on urgency to seek medical attention in case of new onset of rash or fever within 4 weeks following vaccination and (ii) at least one contact with the patient's caregiver in the month following vaccination to identify any adverse event that might have occurred [47].

\section{Concluding discussion}

As many questions remain, clinical trials are still needed to refine the study of the immune response induced by each vaccine in all immunocompromising conditions to determine whether, when and for whom there is a need for a specific immunisation schedule. Moreover, additional guidance regarding the serological monitoring of vaccine response and persistence of protection is required.

As new vaccines become available and the epidemiology of vaccine-preventable diseases evolves, it is increasingly important for all those caring for children to be up to date with the recent changes to guidelines, in order to improve the usual low uptake of additional immunisations in high-risk groups [51]; physician's awareness is key, since it repeatedly correlates with higher vaccination rates [11].

Author contribution LFP drafted the initial manuscript. KMPB critically revised the manuscript and both authors approved the final version as submitted.

Funding Open Access funding provided by Université de Genève. LFP is supported by the Swiss National Science Foundation (Early Postdoc.Mobility grant number P2GEP3_178155).

There is no funding source for this review

Data availability Not applicable.

Code availability Not applicable.

\section{Declarations}

Ethical approval This article does not contain any studies with human participants or animals performed by any of the authors.

Consent to participate Not applicable.

Consent for publication Not applicable.

Conflict of interest The authors declare that they have no conflict of interest.
Open Access This article is licensed under a Creative Commons Attribution 4.0 International License, which permits use, sharing, adaptation, distribution and reproduction in any medium or format, as long as you give appropriate credit to the original author(s) and the source, provide a link to the Creative Commons licence, and indicate if changes were made. The images or other third party material in this article are included in the article's Creative Commons licence, unless indicated otherwise in a credit line to the material. If material is not included in the article's Creative Commons licence and your intended use is not permitted by statutory regulation or exceeds the permitted use, you will need to obtain permission directly from the copyright holder. To view a copy of this licence, visit http://creativecommons.org/licenses/by/4.0/.

\section{References}

1. van Wijhe M, McDonald SA, de Melker HE, Postma MJ, Wallinga J (2016) Effect of vaccination programmes on mortality burden among children and young adults in the Netherlands during the 20th century: a historical analysis. Lancet Infect Dis 16:592-598

2. Feldman AG, Beaty BL, Curtis D, Juarez-Colunga E, Kempe A (2019) Incidence of hospitalization for vaccine-preventable infections in children following solid organ transplant and associated morbidity, mortality, and costs. JAMA Pediatr 173:260-268

3. Kaplan LJ, Daum RS, Smaron M, McCarthy CA (1992) Severe measles in immunocompromised patients. JAMA 267:1237-1241

4. Pittet LF, Abbas M, Siegrist CA, Pittet D (2020) Missed vaccinations and critical care admission: all you may wish to know or rediscover-a narrative review. Intensive Care Med 46:202-214

5. VanderEnde K, Gacic-Dobo M, Diallo MS, Conklin LM, Wallace AS (2018) Global routine vaccination coverage - 2017. MMWR Morb Mortal Wkly Rep 67:1261-1264

6. Luna MS, Manzoni P, Paes B, Baraldi E, Cossey V, Kugelman A, Chawla R, Dotta A, Rodriguez Fernandez R, Resch B, CarbonellEstrany X (2020) Expert consensus on palivizumab use for respiratory syncytial virus in developed countries. Paediatr Respir Rev 33:35-44

7. American Academy of Pediatrics Committee on Infectious Diseases, American Academy of Pediatrics Bronchiolitis Guidelines Committee (2014) Updated guidance for palivizumab prophylaxis among infants and young children at increased risk of hospitalization for respiratory syncytial virus infection. Pediatrics 134:415-420

8. Chinen J, Shearer WT (2010) Secondary immunodeficiencies, including HIV infection. J Allergy Clin Immunol 125:S195-S203

9. Feldman AG, Curtis DJ, Moore SL, Kempe A (2020)Underimmunization of pediatric transplant recipients: a call to action for the pediatric community. Pediatr Res 87:277-281

10. Martinelli M, Giugliano FP, Strisciuglio C, Urbonas V, Serban DE, Banaszkiewicz A, Assa A, Hojsak I, Lerchova T, Navas-Lopez VM, Romano C, Sladek M, Veres G, Aloi M, Kucinskiene R, Miele E (2019) Vaccinations and immunization status in pediatric inflammatory bowel disease: a multicenter study from the Pediatric IBD Porto Group of the ESPGHAN. Inflamm Bowel Dis

11. Giannattasio A, Squeglia V, Lo Vecchio A, Russo MT, Barbarino A, Carlomagno R, Guarino A (2010) Pneumococcal and influenza vaccination rates and their determinants in children with chronic medical conditions. Ital J Pediatr 36:28

12. Doherty M, Schmidt-Ott R, Santos JI, Stanberry LR, Hofstetter AM, Rosenthal SL, Cunningham AL (2016) Vaccination of special populations: Protecting the vulnerable. Vaccine 34:6681-6690 
13. Dipasquale V, Romano C (2017) Vaccination strategies in pediatric inflammatory bowel disease. Vaccine 35:6070-6075

14. Eibl MM, Wolf HM (2015) Vaccination in patients with primary immune deficiency, secondary immune deficiency and autoimmunity with immune regulatory abnormalities. Immunotherapy 7 : 1273-1292

15. Feuerstein JD, Castillo NE, Siddique SS, Lewandowski JJ, Geissler K, Martinez-Vazquez M, Thukral C, Leffler DA, Cheifetz AS (2016) Poor documentation of inflammatory bowel disease quality measures in academic, community, and private practice. Clin Gastroenterol Hepatol 14:421-428.e422

16. Papp KA, Haraoui B, Kumar D, Marshall JK, Bissonnette R, Bitton A, Bressler B, Gooderham M, Ho V, Jamal S, Pope JE, Steinhart AH, Vinh DC, Wade J (2019) Vaccination guidelines for patients with immune-mediated disorders on immunosuppressive therapies. J Cutan Med Surg 23:50-74

17. Obaro SK, Pugatch D, Luzuriaga K (2004) Immunogenicity and efficacy of childhood vaccines in HIV-1-infected children. Lancet Infect Dis 4:510-518

18. Esposito S, Mastrolia MV, Prada E, Pietrasanta C, Principi N (2014) Vaccine administration in children with chronic kidney disease. Vaccine 32:6601-6606

19. Mulley WR, Dendle C, Ling JEH, Knight SR (2018) Does vaccination in solid-organ transplant recipients result in adverse immunologic sequelae? A systematic review and meta-analysis. J Heart Lung Transplant 37:844-852

20. Klein NP, Aukes L, Lee J, Fireman B, Shapira SK, Slade B, Baxter R, Summar M (2011) Evaluation of immunization rates and safety among children with inborn errors of metabolism. Pediatrics 127: e1139-e1146

21. Menni F, Chiarelli G, Sabatini C, Principi N, Esposito S (2012) Vaccination in children with inborn errors of metabolism. Vaccine 30:7161-7164

22. Rubin LG, Levin MJ, Ljungman P, Davies EG, Avery R, Tomblyn M, Bousvaros A, Dhanireddy S, Sung L, Keyserling H, Kang I (2014) 2013 IDSA clinical practice guideline for vaccination of the immunocompromised host. Clin Infect Dis 58:309-318

23. European Centre for Disease Prevention and Control. Vaccine schedules in all countries of the European Union 2020 [Available from: https://vaccine-schedule.ecdc.europa.eu/. Accessed 18 April 2020].

24. Drijkoningen JJ, Rohde GG (2014) Pneumococcal infection in adults: burden of disease. Clin Microbiol Infect 20(Suppl 5):45-51

25. Kantso B, Simonsen J, Hoffmann S, Valentiner-Branth P, Petersen AM, Jess T (2015) Inflammatory bowel disease patients are at increased risk of invasive pneumococcal disease: a nationwide Danish cohort study 1977-2013. Am J Gastroenterol 110:15821587

26. Lebel A, Kropach N, Ashkenazi-Hoffnung L, Huber-Yaron A, Davidovits M (2020) Infections in children with nephrotic syndrome: twenty years of experience. Clin Pediatr (Phila): 9922820908583

27. Di Sabatino A, Carsetti R, Corazza GR (2011) Post-splenectomy and hyposplenic states. Lancet 378:86-97

28. Di Sabatino A, Rosado MM, Ciccocioppo R, Cazzola P, Morera R, Corazza GR, Carsetti R (2005) Depletion of immunoglobulin M memory B cells is associated with splenic hypofunction in inflammatory bowel disease. Am J Gastroenterol 100:1788-1795

29. Robinson CL, Bernstein H, Poehling K, Romero JR, Szilagyi P (2020) Advisory Committee on Immunization Practices recommended immunization schedule for children and adolescents aged 18 years or younger - United States, 2020. MMWR Morb Mortal Wkly Rep 69:130-132

30. Borrow R, Heath PT, Siegrist CA (2012) Use of pneumococcal polysaccharide vaccine in children: what is the evidence? Curr Opin Infect Dis 25:292-303
31. Ortiz JR, Neuzil KM, Shay DK, Rue TC, Neradilek MB, Zhou H, Seymour CW, Hooper LG, Cheng PY, Goss CH, Cooke CR (2014) The burden of influenza-associated critical illness hospitalizations. Crit Care Med 42:2325-2332

32. Acevedo R, Bai X, Borrow R, Caugant DA, Carlos J, Ceyhan M, Christensen H, Climent Y, de Wals P, Dinleyici EC, EchanizAviles G, Hakawi A, Kamiya H, Karachaliou A, Lucidarme J, Meiring S, Mironov K, Sáfadi MAP, Shao Z, Smith V, Steffen R, Stenmark B, Taha MK, Trotter C, Vázquez JA, Zhu B (2019) The Global Meningococcal Initiative meeting on prevention of meningococcal disease worldwide: Epidemiology, surveillance, hypervirulent strains, antibiotic resistance and high-risk populations. Expert Rev Vaccines 18:15-30

33. Reusser NM, Downing C, Guidry J, Tyring SK (2015) HPV carcinomas in immunocompromised patients. J Clin Med 4:260-281

34. Garland SM, Brotherton JML, Moscicki AB, Kaufmann AM, Stanley M, Bhatla N, Sankaranarayanan R, de Sanjose S, Palefsky JM (2017) HPV vaccination of immunocompromised hosts. Papillomavirus Res 4:35-38

35. Lai JJ, Lin C, Ho CL, Chen PH, Lee CH (2019)Alternative-dose versus standard-dose trivalent influenza vaccines for immunocompromised patients: A meta-analysis of randomised control trials. $\mathrm{J}$ Clin Med:8

36. Miskulin D, Weiner DE, Manley HJ (2020)High-dose versus standard-dose influenza vaccine in hemodialysis patients. Am J Kidney Dis 75:456

37. Mombelli M, Kampouri E, Manuel O (2020) Influenza in solid organ transplant recipients: epidemiology, management, and outcomes. Expert Rev Anti Infect Ther 18:103-112

38. Moore DL (2018) Immunization of the immunocompromised child: Key principles. Paediatr Child Health 23:203-205

39. Top KA, Vaudry W, Morris SK, Pham-Huy A, Pernica JM, Tapiero B, Gantt S, Price VE, Rassekh SR, Sung L, McConnell A, Rubin E, Chawla R, Halperin SA (2020) Waning vaccine immunity and vaccination responses in children treated for acute lymphoblastic leukemia: A Canadian Immunization Research Network Study. Clin Infect Dis

40. Lynfield R, Herrin JT, Rubin RH (1992) Varicella in pediatric renal transplant recipients. Pediatrics 90:216-220

41. Feldhoff CM, Balfour HH Jr, Simmons RL, Najarian JS, Mauer SM (1981) Varicella in children with renal transplants. J Pediatr 98:2531

42. Lachiewicz AM, Srinivas ML (2019)Varicella-zoster virus postexposure management and prophylaxis: A review. Prev Med Rep 16:101016

43. Sobh A, Bonilla FA (2016) Vaccination in primary immunodeficiency disorders. J Allergy Clin Immunol Pract 4:1066-1075

44. Fekrvand S, Yazdani R, Olbrich P, Gennery A, Rosenzweig SD, Condino-Neto A, Azizi G, Rafiemanesh H, Hassanpour G, Rezaei N, Abolhassani H, Aghamohammadi A (2020) Primary immunodeficiency diseases and Bacillus Calmette-Guerin (BCG)-vaccinederived complications: a systematic review. J Allergy Clin Immunol Pract

45. Panel on Opportunistic Infections in HIV-Infected Adults and Adolescents. Recommended immunization schedule for adults and adolescents with HIV infection. [updated 13 Sept 2017, available from: http://aidsinfo.nih.gov/contentfiles/lvguidelines/adult oi.pdf. Accessed 17 May 2020].

46. Scott P, Moss WJ, Gilani Z, Low N (2011) Measles vaccination in HIV-infected children: systematic review and meta-analysis of safety and immunogenicity. J Infect Dis 204(Suppl 1):S164-S178

47. Suresh S, Upton J, Green M, Pham-Huy A, Posfay-Barbe KM, Michaels MG, Top KA, Avitzur Y, Burton C, Chong PP, Danziger-Isakov L, Dipchand AI, Hebert D, Kumar D, Morris SK, Nalli N, Ng VL, Nicholas SK, Robinson JL, Solomon M, Tapiero B, Verma A, Walter JE, Allen UD (2019) Live vaccines 
after pediatric solid organ transplant: proceedings of a consensus meeting, 2018. Pediatr Transplant:e13571

48. Patel S, Heath P, Skinner R. Vaccinations for paediatric patients treated with standard-dose chemotherapy and hematopoietic stem cell transplantation (HSCT) recipients 2017 [updated Sept 2017, available from: https://www.cclg.org.uk/write/MediaUploads/ Member\%20area/Treatment\%20guidelines/Vaccinations_for Children_treated_with_Standard-dose_Chemotherapy_and HSCT_Recipients-Sept_2014-FINAL_CCLG.pdf. Accessed $\overline{8}$ Feb 2020]

49. Ljungman P, Cordonnier C, Einsele H, Englund J, Machado CM, Storek J, Small T, Center for International B, Marrow Transplant R, National Marrow Donor P, European B, Marrow Transplant G, American Society of B, Marrow T, Canadian B, Marrow Transplant G, Infectious Disease Society of A, Society for Healthcare Epidemiology of A, Association of Medical M, Infectious Diseases C, Centers for Disease C, Prevention (2009) Vaccination of hematopoietic cell transplant recipients. Bone Marrow Transplant 44:521-526

50. Kamei K, Miyairi I, Ishikura K, Ogura M, Shoji K, Funaki T, Ito R, Arai K, Abe J, Kawai T, Onodera M, Ito S (2018) Prospective study of live attenuated vaccines for patients with nephrotic syndrome receiving immunosuppressive agents. J Pediatr 196:217-222.e211

51. Pinto MV, Bihari S, Snape MD (2016) Immunisation of the immunocompromised child. J Infect 72(Suppl):S13-S22

52. Bonilla FA (2018) Update: Vaccines in primary immunodeficiency. J Allergy Clin Immunol 141:474-481

53. Medical Advisory Committee of the Immune Deficiency Foundation, Shearer WT, Fleisher TA, Buckley RH, Ballas Z, Ballow M, Blaese RM, et al. (2014) Recommendations for live viral and bacterial vaccines in immunodeficient patients and their close contacts. J Allergy Clin Immunol 133:961-966

54. Martire B, Azzari C, Badolato R, Canessa C, Cirillo E, Gallo V, Graziani S, Lorenzini T, Milito C, Panza R, Moschese V, with Italian Network for Primary Immunodeficiencies (2018) Vaccination in immunocompromised host: Recommendations of Italian Primary Immunodeficiency Network Centers (IPINET). Vaccine 36:3541-3554

55. Cesaro S, Giacchino M, Fioredda F, Barone A, Battisti L, Bezzio S, Frenos S, De Santis R, Livadiotti S, Marinello S, Zanazzo AG, Caselli D (2014) Guidelines on vaccinations in paediatric haematology and oncology patients. Biomed Res Int 2014:707691

56. Menson EN, Mellado MJ, Bamford A, Castelli G, Duiculescu D, Marczynska M, Navarro M, Scherpbier HJ, Heath PT (2012) Guidance on vaccination of HIV-infected children in Europe. HIV Med 13(333-336):e331-e314
57. Benamu E, Montoya JG (2016) Infections associated with the use of eculizumab: recommendations for prevention and prophylaxis. Curr Opin Infect Dis 29:319-329

58. Gagneur A, Pinquier D, Quach C (2015) Immunization of preterm infants. Hum Vaccin Immunother 11:2556-2563

59. Calliari LE, Almeida FJ, Noronha RM (2020) Infections in children with diabetes. J Pediatr (Rio J) 96:39-46

60. Husein N, Chetty A (2018) Influenza, pneumococcal, hepatitis b and herpes zoster vaccinations. Can J Diabetes 42(Suppl 1):S142s144

61. World Federation of Hemophilia. Guidelines for the Management of Hemophilia 2012 [Available from: https:/elearning.wfh.org/ resource/treatment-guidelines/. Accessed 18 April 2020].

62. Gibson D, Mehler PS (2019) Anorexia nervosa and the immune system-a narrative review. J Clin Med 8

63. Andersen CJ, Murphy KE, Fernandez ML (2016) Impact of obesity and metabolic syndrome on immunity. Adv Nutr 7:66-75

64. Kelishadi R, Roufarshbaf M, Soheili S, Payghambarzadeh F, Masjedi M (2017) Association of childhood obesity and the immune system: a systematic review of reviews. Child Obes 13:332-346

65. Tagliabue C, Principi N, Giavoli C, Esposito S (2016) Obesity: impact of infections and response to vaccines. Eur J Clin Microbiol Infect Dis 35:325-331

66. Snyder J, Butzner JD, DeFelice AR, Fasano A, Guandalini S, Liu E, Newton KP (2016)Evidence-informed expert recommendations for the management of celiac disease in children. Pediatrics:138

67. Simons M, Scott-Sheldon LAJ, Risech-Neyman Y, Moss SF, Ludvigsson JF, Green PHR (2018) Celiac disease and increased risk of pneumococcal infection: a systematic review and meta-analysis. Am J Med 131:83-89

68. Dinleyici M, Carman KB, Kilic O, Laciner Gurlevik S, Yarar C, Dinleyici EC (2018) The immunization status of children with chronic neurological disease and serological assessment of vaccinepreventable diseases. Hum Vaccin Immunother 14:1970-1976

69. Kienast AK, Kreth HW, Hoger PH (2007) Varicella vaccination in children with atopic eczema. J Dtsch Dermatol Ges 5:875-880

70. Plotkin SA (2010) Correlates of protection induced by vaccination. Clin Vaccine Immunol 17:1055-1065

71. Plotkin SA (2008) Vaccines: correlates of vaccine-induced immunity. Clin Infect Dis 47:401-409

72. Plotkin SA, Orenstein WA, Offit PA (2012) Vaccines.6th edition edn. Elsevier, Philadelphia, PA

Publisher's note Springer Nature remains neutral with regard to jurisdictional claims in published maps and institutional affiliations. 